\title{
Os significados do número racional na formação continuada de professores de Matemática
}

The meanings of the rational number in the continuing formation of mathematics teachers

\author{
Danusa de Lara Bonotto ${ }^{1}$ \\ Izabel Gioveli ${ }^{2}$
}

\section{Resumo}

Este texto apresenta resultados da pesquisa que tem como objetivo compreender como o professor de Matemática (re)configura os diferentes significados do número racional a partir da formação continuada. Para tal, utilizou-se o Interacionismo Sociodiscursivo como aporte teórico-metodológico e analítico o qual permitiu, inicialmente, a identificação dos conteúdos tematizados em quatro encontros de formação continuada. As participantes da pesquisa são seis professoras de Matemática da Educação Básica. Os dados empíricos são constituídos a partir de audiogravação e transcrição dos encontros de formação. Os resultados assinalam que o professor de Matemática (re)configura os diferentes significados do número racional durante as interações discursivas estabelecidas no grupo: nas discussões e dúvidas apresentadas durante a resolução dos problemas propostos e nos conflitos estabelecidos na relação das professoras com esse instrumento simbólico o que potencializou reflexões sobre o agir docente e novas formas de (re)organizar o seu trabalho.

Palavras-chave: Trabalho docente. Formação continuada de professores. Números racionais.

\section{Introdução}

Esta pesquisa desenvolveu-se no contexto de um programa de extensão envolvendo formação continuada de professores e realizado na Universidade Federal da Fronteira Sul, campus Cerro Largo/RS. O programa denominado Ciclos Formativos em Ensino de Ciências e Matemática é desenvolvido por professores das áreas de Matemática, Física, Biologia e Química da universidade.

${ }^{1}$ Doutora em Educação em Ciências e Matemática - PUCRS, professora de Matemática e do Programa de Pós-Graduação em Ensino de Ciências, Universidade Federal da Fronteira Sul Campus Cerro Largo, danusalb@uffs.edu.br.

${ }^{2}$ Doutora em Engenharia - UFRGS, professora de Matemática, Universidade Federal da Fronteira Sul - Campus Cerro Largo, iza.gioveli@uffs.edu.br. 
As ações do programa são conduzidas tendo como fundamento a investigaçãoformação-crítica entrelaçada com a perspectiva do professor reflexivo e pesquisador, isso defendido como uma possibilidade de formação de professores. A metodologia empregada prioriza encontros e reflexões coletivas em torno dos temas de interesse apresentados pelos professores da Educação Básica, participantes da formação. De modo específico, neste texto dedica-se atenção à formação realizada com os professores de Matemática. Atualmente, participam do grupo duas professoras da área de Matemática da universidade e seis professoras de Matemática da Educação Básica dos níveis fundamental e médio de ensino da rede pública da região de abrangência da universidade.

Os encontros do grupo de Matemática acontecem mensalmente na universidade, são audiogravados e possuem duração de aproximadamente três horas. Nesses encontros, realizam-se estudos e discussões sobre as tendências temáticas da Educação Matemática, bem como, o planejamento e análise de forma colaborativa de estratégias pedagógicas envolvendo os pressupostos dessas tendências e socialização das práticas e das escritas desenvolvidas pelas professoras participantes.

Juntamente a essas ações de formação articulam-se atividades de ensino e pesquisa. Nesse contexto, apresenta-se um recorte desse processo formativo 0 qual envolveu o estudo dos diferentes significados do número racional, conforme entendimento de Onuchic e Allevato (2008). Desse modo, o objetivo desta pesquisa consiste em compreender como o professor de Matemática (re)configura os diferentes significados do número racional a partir da formação continuada. Para tanto, identificaram-se os conteúdos temáticos textualizados em quatro encontros de formação e o que eles mostram sobre o trabalho do professor de Matemática e os significados do número racional.

Organizou-se este texto apresentando o Interacionismo Sociodiscursivo (ISD) e a noção de trabalho docente. Na sequência, o entendimento dos diferentes significados do número racional na perspectiva de Onuchic e Allevato (2008); as perspectivas metodológicas, bem como, a análise e discussão. Por fim, 
apresentam-se as considerações e perspectivas de continuidade acerca da pesquisa por ora realizada.

\section{O Interacionismo Sociodiscursivo e a noção de trabalho docente}

O ISD estuda o agir humano tendo como foco principal a linguagem e tem como principal representante Bronckart (2006, 2008, 2012). Esse referencial teórico-metodológico e analítico tem sido utilizado também para estudar as relações entre a linguagem e o trabalho educacional, por meio da análise de textos produzidos na e sobre a situação de trabalho. O ISD defende que os textos são o instrumento no qual e pelo qual o ser humano emite interpretações e avaliações relativas ao seu agir, podendo contribuir para clarificar e transformar esse agir (MACHADO et al., 2009). Assim, neste estudo, é por meio da linguagem, dos textos produzidos durante quatro encontros de formação que se pretende compreender como o professor de Matemática (re)configura os diferentes significados do número racional.

Em relação ao entendimento sobre trabalho, à luz do ISD o trabalho é considerado, conforme Bronckart (2006, p. 209) como uma forma de agir, "como um tipo de atividade ou prática" própria da espécie humana, a qual se desenvolve num contexto social específico, por meio das atividades coletivas organizadas.

Assim, Machado e Bronckart (2009) compreendem o trabalho do professor como uma atividade que não é isolada, mas inscrita num contexto sócio-histórico, inserido em um sistema de ensino e num sistema educacional específico. $O$ esquema da Figura 01 expressa as representações sobre os elementos constitutivos do agir docente e das relações que mantêm entre si. 


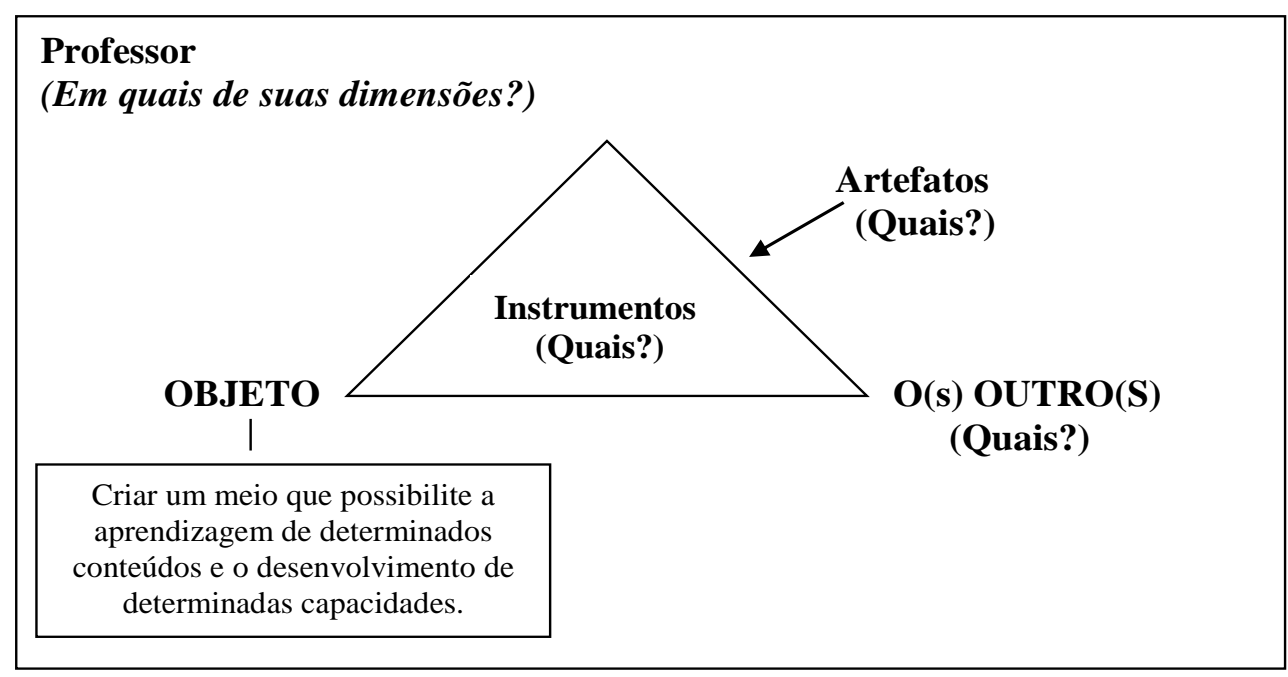

Figura 01: Esquema do trabalho do professor em sala de aula Fonte: Adaptado de Machado e Bronckart (2009, p.39)

O esquema, na figura apresentada, expressa que o trabalho do professor em sala de aula,

Mobiliza seu ser integral, em suas diferentes dimensões (físicas,
cognitivas, linguageiras, afetivas, etc.), com o objetivo de criar um
meio propício à aprendizagem de determinados conteúdos e ao
desenvolvimento de determinadas capacidades dos alunos. A
realização dessa atividade é sempre orientada por prescrições e
por modelos do agir, que são apropriados pelo professor e
desenvolvidos em interação permanente com a atividade de
outros actantes (dos alunos principalmente) e com a utilização de
instrumentos materiais ou simbólicos, oriundos da apropriação de
artefatos disponibilizados pelo meio social. (MACHADO;
BRONCKART, 2009, p. 40).

Nesse viés, os pressupostos teóricos referentes aos diferentes significados do número racional constituem-se em artefato simbólico. Ao apresentar problemas envolvendo os diferentes significados em sala de aula, o artefato simbólico se torna instrumento para o agir do professor e provoca transformações não apenas sobre o objeto, mas também sobre os outros indivíduos envolvidos na atividade e sobre o próprio professor.

Neste trabalho, a partir das atividades realizadas na formação continuada acerca dos diferentes significados do número racional e dos conteúdos 
tematizados nos encontros de formação, busca-se compreender como o professor (re)configura esses diferentes significados.

\section{Perspectivas metodológicas}

Considerando o objetivo da pesquisa, classifica-se a mesma como sendo de natureza qualitativa, visto que preocupa-se com a compreensão detalhada dos significados e características das situações investigadas. (BOGDAN; BIKLEN, 1994).

Os sujeitos da pesquisa são seis professoras ${ }^{3}$ de Matemática da Educação Básica, as quais participam do programa de formação continuada. A constituição dos dados deu-se por meio do material audiogravado e posteriormente transcrito de quatro encontros de formação, nos quais estudou-se acerca dos diferentes significados do número racional. Os textos que compõem o corpus de análise são constituídos pelas interações discursivas referentes, apenas, aos números racionais.

A análise do material transcrito segue os procedimentos do ISD, os quais são inspirados nas abordagens interacionistas de Bakhtin/Volochinov (1997) e Bakhtin (1992) e, segundo Bronckart (2006, 2008), adota um método de análise descendente, ou seja, parte das atividades sociais e das atividades de linguagem e dessas aos textos e às formas linguísticas que o compõem. A análise proposta envolve a identificação do contexto de produção dos textos e a organização das análises textuais nos níveis denominados de organizacional, enunciativo e semântico. O contexto de produção fornece informações sobre o contexto físico e sociossubjetivo nos quais os textos foram produzidos. Já no que concerne aos níveis de análise textual, o nível organizacional permite a identificação dos conteúdos tematizados e dos tipos de discurso utilizados. No nível enunciativo, as estruturas observadas dizem respeito às marcas de pessoa e à inserção de vozes e modalizações. O nível semântico permite a identificação das figuras

3 As professoras participantes são nominadas por: A, B, C, D, E e F, a fim de preservar suas identidades. 
interpretativas do agir: razões, intencionalidade e recursos. Neste estudo dá-se atenção a um recorte do processo de análise: a identificação do conteúdo temático referente ao primeiro nível de análise textual - nível organizacional.

\section{As atividades realizadas com as professoras}

Decorrente do estudo realizado por Bonotto e Gioveli (2018), o grupo de professoras em formação continuada propõe-se a estudar e discutir os diferentes significados do número racional. Para tal, utilizou-se inicialmente o artigo As diferentes "personalidades" do número racional trabalhadas através da Resolução de Problemas, de Onuchic e Allevato (2008). A partir da resolução e discussão dos problemas propostos no artigo, observou-se a necessidade da realização de novos problemas a fim de favorecer às participantes maior compreensão acerca dos diferentes significados do número racional.

Desse modo, considerando o contexto de trabalho das professoras participantes da formação e, no período do estudo, a realização da prova da Olimpíada Brasileira de Matemática das Escolas Públicas - OBMEP, elas manifestaram o interesse na resolução das questões propostas nessa prova. Assim, entrelaçando o estudo que estava sendo realizado e as dificuldades advindas da identificação dos diferentes significados, foi proposto pelas professoras formadoras o olhar para esses diferentes significados do número racional nas provas da OBMEP. Para isso, selecionaram-se as provas realizadas nos últimos três anos (2016-2018) e realizou-se a leitura das mesmas identificando as questões que abordassem números racionais. Na sequência, realizou-se a resolução dessas questões identificando, em cada uma delas, o significado do número racional predominante.

O quadro 01 apresenta a síntese das atividades realizadas nos quatro encontros de formação continuada. 


\begin{tabular}{|l|l|}
\hline \multicolumn{1}{|c|}{ Encontros } & \multicolumn{1}{c|}{ Organização do encontro } \\
\hline 10 encontro $^{\circ}$ & Leitura e discussão do artigo de Onuchic e Allevato (2008) \\
\hline 20 encontro & $\begin{array}{l}\text { Leitura e discussão do artigo de Onuchic e Allevato (2008), com } \\
\text { enfoque para a resolução dos problemas. }\end{array}$ \\
\hline $3^{\circ}$ encontro & $\begin{array}{l}\text { Resolução das questões das provas da OBMEP- 2016-2018 } \\
\text { referente aos níveis 1 e 2. }\end{array}$ \\
\hline $\mathbf{4}^{\circ}$ encontro & $\begin{array}{l}\text { Resolução das questões das provas da OBMEP- 2016-2018 } \\
\text { referente aos níveis 1 e 2. }\end{array}$ \\
\hline
\end{tabular}

Quadro 01: Encontros de Formação Continuada

Fonte: Elaborado pelas autoras.

A seguir, apresenta-se o entendimento dos diferentes significados do número racional, bem como exemplos de questões advindas das provas da OBMEP as quais priorizam esses significados.

\section{Números racionais: diferentes significados nas provas da OBMEP}

O estudo de números racionais faz-se presente na Educação Básica desde os anos iniciais do nível fundamental de ensino. Na Base Nacional Comum Curricular - BNCC, consta que os alunos precisam desenvolver as ideias de aproximação, proporcionalidade, equivalência e ordem e, para tal, sugere-se a realização de situações que potencializem sucessivas ampliações dos campos numéricos enfatizando registros, usos, significados e operações (BRASIL, 2018).

Para Onuchic e Allevato (2008, p. 81), "o ensino e a aprendizagem dos conceitos relacionados aos números racionais, permanecem um sério obstáculo no desenvolvimento matemático dos alunos". As autoras apontam para a necessidade de compreender com clareza os diferentes significados - ponto racional, quociente, fração, razão e operador - do número racional, a fim de potencializar a organização de experiências de aprendizagem para os estudantes. Os diferentes significados dos números racionais, de acordo com as autoras são:

- ponto racional: refere-se à localização do número racional na reta numérica. Destaca-se que a BNCC sugere a utilização da reta numérica desde os anos iniciais do Ensino Fundamental. De forma específica, no quarto ano do 
Ensino Fundamental tem-se a utilização da reta numérica como recurso para marcar números racionais menores do que a unidade.

- quociente: considera um número de objetos repartido igualmente num certo número de grupos e refere-se ao uso dos números racionais como solução para uma situação de divisão.

- fração: refere-se à relação da parte com o todo.

- operador: envolve ações como 'encolher - esticar' ou 'reduzir - ampliar'.

- razão: refere-se a uma comparação multiplicativa entre duas grandezas e fundamenta um conceito importante da Matemática que é o conceito de proporcionalidade.

As professoras participantes da formação continuada possuem maior inserção no nível fundamental de ensino. Diante disso, realizou-se o estudo apenas dos níveis 1 e 2 da prova da OBMEP. O nível 1 (N1) compreende o 6o e $7^{\circ}$ anos do ensino fundamental e o nível 2 (N2) compreende o $8^{\circ}$ e $9^{\circ}$ anos desse nível. Na primeira fase, as provas possuem 20 questões objetivas. Já na segunda fase, a prova é de cunho dissertativo e possui seis questões. O Quadro 02 apresenta a quantificação e classificação das questões conforme os significados privilegiados.

\begin{tabular}{|c|c|c|c|c|c|c|c|c|c|c|}
\hline \multirow[b]{2}{*}{ Significados } & \multicolumn{2}{|c|}{$\begin{array}{c}2016 \\
\text { 19 Fase }\end{array}$} & \multicolumn{2}{|c|}{$\begin{array}{c}2016 \\
\text { 2 }^{\text {a Fase }}\end{array}$} & \multicolumn{2}{|c|}{$\begin{array}{c}2017 \\
\text { 19 Fase }\end{array}$} & \multicolumn{2}{|c|}{$\begin{array}{c}2017 \\
\text { 2 }^{a} \text { Fase }\end{array}$} & \multicolumn{2}{|c|}{$\begin{array}{c}2018 \\
\text { 19 Fase }\end{array}$} \\
\hline & N1 & N2 & N1 & N2 & N1 & N2 & N1 & N2 & N1 & N2 \\
\hline $\begin{array}{c}\text { Ponto } \\
\text { Racional }\end{array}$ & - & - & - & - & - & - & - & - & - & - \\
\hline Quociente & - & - & - & - & - & - & - & - & - & - \\
\hline Fração & 2 & 4 & 1 & 0 & 2 & 2 & 1 & 1 & 3 & 1 \\
\hline Operador & - & - & - & - & - & - & - & - & - & - \\
\hline Razão & - & - & - & - & 1 & 1 & - & - & 1 & 2 \\
\hline Total & & ; & & 1 & & ; & & $?$ & & 7 \\
\hline
\end{tabular}

Quadro 02: Número de questões e significados predominantes nas provas da OBMEP $2016-2018$.

Fonte: Elaborado pelas autoras. 
Observa-se no quadro apresentado, no período analisado, o predomínio do significado de fração e razão. Os significados ponto racional, quociente e operador não foram identificados. O Quadro 03 exemplifica os significados fração e razão, predominantes nas provas analisadas.

\begin{tabular}{|l|l|}
\hline \multicolumn{1}{|c|}{ Significado } & \multicolumn{1}{c|}{ Questão na prova da OBMEP } \\
\hline Fração & $\begin{array}{l}\text { Juca colocou algumas bolinhas em uma caixa na qual cabem, } \\
\text { no máximo, 100 bolinhas. Artur tirou 1/2 das bolinhas dessa } \\
\text { caixa, depois Bernardo tirou 1/3 das restantes, em seguida } \\
\text { Carlos tirou 1/4 das que sobraram e, finalmente, Danilo tirou 1/5 } \\
\text { das que restaram. Quantas bolinhas ficaram na caixa? } \\
\text { Prova OBMEP - 2018, questão 5 - 1a Fase/N2 }\end{array}$ \\
\hline Razão & $\begin{array}{l}\text { Para obter tinta de cor laranja, devem-se misturar 3 partes de } \\
\text { tinta vermelha com 2 partes de tinta amarela. Para obter tinta de } \\
\text { cor verde, devem-se misturar 2 partes de tinta azul com 1 parte } \\
\text { de tinta amarela. Para obter tinta de cor marrom, deve-se } \\
\text { misturar a mesma quantidade de tintas laranja e verde. Quantos } \\
\text { litros de tinta amarela são necessários para obter 30 litros de } \\
\text { tinta marrom? } \\
\text { Prova OBMEP - 2017, questão 11 - 1a Fase/N1 }\end{array}$ \\
\hline
\end{tabular}

Quadro 03: Significados do número racional (fração e razão) nas provas da OBMEP.

Fonte: Elaborado pelas autoras.

Durante a análise das provas da OBMEP, na resolução e discussão das questões, as professoras utilizaram diferentes estratégias de resolução, por vezes, diferentes da resolução apresentada no gabarito das provas. Destaca-se que durante a resolução de um problema, podem surgir diferentes significados do número racional. Entretanto, no Quadro 02 quantifica-se o significado predominante na questão.

\section{Análise e discussão}

O processo de análise, à luz do ISD, permitiu a identificação dos conteúdos tematizados em quatro encontros de formação continuada nos quais se estudaram sobre os números racionais e seus significados. O Quadro 04 apresenta esses conteúdos. 


\begin{tabular}{|c|c|}
\hline Encontros & Conteúdos tematizados \\
\hline $1^{\circ}$ encontro & $\begin{array}{l}\text { - Dificuldades do trabalho na sala de aula. } \\
\text { - Prescrições: currículo - tempo para cumprir o currículo. } \\
\text { - Livro didático. } \\
\text { - Notação e simbologia dos números racionais. } \\
\text { - Ponto racional (dificuldades de localização, noção de aproximação). } \\
\text { - Significado fração e quociente - resolução de problemas. } \\
\text { - Contexto financeiro para abordagem de números racionais. }\end{array}$ \\
\hline $2^{\circ}$ encontro & $\begin{array}{l}\text { - Condição de trabalho: tempo para planejar e escrever. } \\
\text { - Dificuldades dos alunos para marcar números racionais na reta } \\
\text { numérica. } \\
\text { - Discussão do significado razão, quociente e operador e resolução de } \\
\text { problemas. }\end{array}$ \\
\hline $\begin{array}{l}3^{\circ} \text { encontro } \\
\text { e } \\
4^{\circ} \text { encontro }\end{array}$ & $\begin{array}{l}\text { - Escrita do diário referente aos encontros de formação. } \\
\text { - Desconhecimento dos diferentes significados pelas professoras de } \\
\text { modo geral. } \\
\text { - Prescrições: BNCC } \\
\text { - Livro didático } \\
\text { - Ponto racional e a noção de aproximação. } \\
\text { - Diferentes significados na resolução de um problema. } \\
\text { - Avaliações sobre a prova da OBMEP } \\
\text { - Importância do registro figural ao trabalhar com o significado de } \\
\text { fração. }\end{array}$ \\
\hline
\end{tabular}

Quadro 04: Conteúdos tematizados nos encontros de formação continuada.

Fonte: Elaborado pelas autoras.

Destaca-se que além das informações apresentadas no Quadro 04, são tematizados nos encontros outras informações, as quais não estão articuladas ao objeto de análise deste estudo, mas dizem respeito: à trajetória construída pelo grupo como uma espaço/tempo para estudo, qualificação, discussão e pesquisa; ao sentimento de pertencimento ao grupo; ao planejamento de ações e compartilhamento de assuntos pessoais, dentre outros.

No primeiro encontro de formação, ao iniciarem o estudo dos significados do número racional, as professoras participantes textualizaram elementos importantes do trabalho docente: currículo, livro didático, aspectos específicos do trabalho na sala de aula (tempo de aprendizagem descompassado do tempo escolar, falta de vontade dos alunos), dificuldade dos estudantes para interpretar problemas e seus resultados. Além disso, no decorrer do encontro, há relatos de práticas realizadas pelas professoras envolvendo números racionais. Por meio desses relatos identificaram-se aspectos que instituem as características do 
trabalho docente referentes: as suas concepções de ensino, à abordagem dos números racionais e à compreensão pelas professoras dos diferentes significados desses números. Os relatos desses episódios da prática marcam: a utilização de contextos do cotidiano envolvendo valores financeiros, a simbologia e notação para a escrita desses números, a marcação na reta numérica do número racional (ponto racional) e a noção de aproximação.

No segundo encontro de formação, os estudos e as discussões sobre os diferentes significados do número racional tiveram continuidade. De forma específica, estudou-se o significado de quociente, operador e razão. Durante esse encontro emergiram questões referentes às condições de trabalho do professor (tempo para planejamento, para estudo, para o processo de escrita ${ }^{4}$ ); dúvidas em relação aos diferentes significados do número racional e como identificá-los. Além disso, durante a resolução dos problemas propostos em Onuchic e Allevato (2008), as professoras textualizaram estratégias pessoais e sinalizaram possíveis dificuldades que os estudantes poderiam apresentar, ou seja, observou-se um movimento formativo de reflexão para a prática docente. Ademais, nos momentos de resolução e socialização da resolução dos problemas, há indícios de (re)configurações sobre o entendimento dos significados dos números racionais. Esses aspectos são melhores detalhados no decorrer deste texto.

No terceiro e quarto encontros de formação identificaram-se as questões propostas na prova da OBMEP (2016-2018, referente aos níveis 1 e 2) envolvendo números racionais, bem como realizaram-se a resolução e discussão dessas questões e a identificação do significado predominante, conforme apresentado no Quadro 02. Durante a resolução das questões, as professoras utilizaram estratégias pessoais e compartilharam a abordagem dos números racionais nos livros didáticos utilizados por elas e as estratégias utilizadas por alguns de seus alunos para a resolução das questões da primeira fase de 2018 dos níveis 1 e 2, as quais elas acompanharam. Na resolução dessas questões as

\footnotetext{
4 A escrita refere-se aos diários dos encontros de formação continuada e também das práticas realizadas em sala de aula.
} 
professoras evidenciaram a predominância do significado de fração, utilizando o registro figural como estratégia para a compreensão do problema. Além disso, destaca-se que, dependendo da estratégia utilizada, as professoras identificaram diferentes significados do número racional, durante a resolução de um mesmo problema. Na sequência, detalham-se os conteúdos tematizados, referentes aos números racionais, ancorados nos textos advindos dos encontros de formação continuada.

Em relação aos números racionais textualizou-se no grupo como consenso que o trabalho com esses números se constitui numa dificuldade para o ensino e aprendizagem de Matemática e, ainda, que essas dificuldades surgem com maior ênfase durante a abordagem das quatro operações fundamentais com números racionais nos anos finais do ensino fundamental. De acordo com Onuchic e Allevato (2008), isso também é consenso entre os educadores matemáticos conforme mencionado: "o ensino e aprendizagem dos conceitos relacionados aos números racionais permanecem um sério obstáculo no desenvolvimento matemático dos alunos" (p.81). Por outro lado, evidenciou-se que ao trabalhar número racionais (significado fração) nos anos iniciais do ensino fundamental utilizando contextos advindos da realidade, os alunos compreendem o significado de fração e demonstram interesse em aprender esse conteúdo, conforme a passagem a seguir.

Professora D: Ano passado, foi o primeiro ano que dei aula para o quarto ano, que introduz as frações. Eu trabalhei só a parte prática. Trabalhei as operações, mas só com denominadores iguais e mais na prática. Eles adoraram [...] e esse ano eles ficam pedindo: quero frações. Eu pensei: como eu vou fazer para que eles continuem gostando de frações? No quinto ano, começa as operações, o $\mathrm{mmc}$, não traz para a realidade, é mais automático. Daí eles perdem um pouco o gosto.

Do exposto, cumpre destacar segundo a BNCC, que para a aprendizagem de certo conceito ou procedimento, é fundamental haver um contexto que tenha significado para os alunos. Entretanto, é necessário que eles desenvolvam a capacidade de abstrair o contexto, apreendendo relações e significados para 
aplicá-los em outros contextos. (BRASIL, 2018). Além disso, 1) qual seria a razão dos estudantes gostarem de estudar frações nos anos iniciais e perderem este encantamento nos anos finais? 2) Por que o professor não consegue dar continuidade ao trabalho prático realizado nos anos iniciais? A primeira questão é respondida pela própria professora no final da passagem apresentada ao remeterse ao início do estudo das operações envolvendo frações e o distanciamento desse estudo das situações da realidade. Já a resposta para a segunda questão apresentada é mais complexa e envolve outros elementos do trabalho docente: o papel das prescrições, o tempo para o planejamento e desenvolvimento de atividades diferenciadas, o interesse dos estudantes, o número de alunos por turma, dentre outros.

Ainda, no primeiro encontro de formação continuada, no qual estudou-se o significado ponto racional, as professoras sinalizam para dificuldades de natureza semântica, conforme apresentado por Onuchic e Allevato (2008). O Episódio 1 denota esse movimento:

\section{Episódio 1.}

Professora F: Professora (referindo-se à professora formadora B), eu solicitei para meus alunos marcarem o número racional $1 / 2$ na reta numérica e a resposta deles foi 'entre 1 e 2' e, na sequência, como marcar $2 / 3$ e um aluno respondeu 'entre 2 e 3'.

Esse episódio denota a confusão realizada pelos estudantes advinda da combinação dos números apresentados, o que pode interferir na compreensão do significado ponto racional.

A professora B colabora com essa discussão relatando sua experiência de sala de aula utilizando o contexto monetário e a noção de aproximação para explicar a localização dos números racionais na reta numérica, conforme Episódio 2:

\section{Episódio 2.}

Professora formadora B: Quando pedimos para os alunos marcarem 1/3 na reta numérica, o que acontece?

Professora B: Eu levo eles a fazerem esse pensamento: $R \$ 1,00$ dividido entre 3 pessoas, vai dar $R \$ 0,30$ para cada um e sobra $R \$ 0,10$. Quem vai 
ficar com os $R \$ 0,10$ ? Divide novamente em 3 pessoas, cada uma recebe $R \$$ 0,03 . Tá, sobrou $R \$ 0,01$. Tá, daí quando chega em $R \$ 0,01$ não dá mais para dividir, porque para eles (para os alunos) dinheiro vai até duas casas decimais.

Do exposto, observa-se que a professora utilizou um contexto cotidiano para favorecer a compreensão dos estudantes e utilizar a representação decimal aproximada para marcar na reta numérica o número racional 1/3.

A partir das discussões realizadas, a professora formadora B reforça que todo número racional tem um 'lugar bem definido' na reta numérica e que 1/3 não é 0,3; nem 0,33; nem 0,333, mas deve-se considerar o segmento unitário, dividi-lo em três partes e marcar a primeira delas.

Ademais, identificou-se que, costumeiramente, esse significado não é abordado com a exatidão exigida durante os anos finais do ensino fundamental. Isso é marcado na fala da professora F ao textualizar:

Professora F: Quando eu fiz o meu estágio, a gente fez desse modo: dividia em tantas partes, tipo o 1/3 em três partes e pega uma. Só que hoje, a gente vai pelo 'mais ou menos', porque tu não trabalha muito a questão da reta né. Ai tu faz pelo 'mais ou menos'. Divide e vê 'mais ou menos' para marcar.

Observa-se na passagem apresentada, que a abordagem do significado ponto racional envolve a noção de aproximação, a qual não clarifica que todo número racional possui um lugar bem definido na reta numérica.

O significado quociente gerou discussões durante a resolução do problema: "Três pizzas devem ser divididas igualmente entre cinco pessoas. Quanto de pizza cada pessoa comerá?" (ONUCHIC; ALLEVATO, 2008, p. 88).

A percepção das professoras formadoras durante a resolução desse problema foi que o significado fração surgiu com maior ênfase dificultando a compreensão do significado quociente. As passagens, a seguir, ilustram dois episódios:

\section{Episódio 3.}

Professora A: Cada pizza a gente divide em 5 pessoas. Cada pessoa receberá 3/5. Com o desenho é mais fácil que com a conta (referindo-se à representação figural). 
Professora formadora A: (Faz desenho no quadro com tamanhos de pizzas diferentes)

Professora A: Tanto faz o tamanho profe, a gente conta os pedaços.

Professora formadora A: Tá, então da primeira pizza cada pessoa recebe 1/5. Da segunda 1/5 e da terceira 1/5. Portanto cada pessoa comerá $3 / 5$ de pizza.

\section{Episódio 4.}

Professora A: Mas o total de pedaços seriam quinze né? Daí daria 3 pedaços para cada um.

Professora B: Quinze pedaços dividido por cinco pessoas dá 3 pedaços para cada uma. (Professora B reforça o que a professora A falou)

Professora formadora B: Qual a diferença de pensar assim e pensar do outro jeito? Teria problema em pensar em 15 pedaços? (Professora formadora B referindo-se ao Episódio 3)

Professora A: O tamanho do pedaço.

Professora D: Mas quinze pedaços dividindo por cinco dá três pedaços para cada um. (Professora D reforçando o que as professoras A e B falaram)

Professora E: Tu vai fazer 1/5 + 1/5 + 1/5 dá 3/5 é diferente de 15/5.

Os Episódios 3 e 4 apresentados denotam percepções diferentes acerca do mesmo problema. No Episódio 3, tem-se o significado quociente - um número de objetos divido num certo número de grupos, ou seja, três pizzas dividas entre cinco pessoas. Entretanto, nas discussões durante a resolução do problema surge o significado de fração quando as professoras pensam que as três pizzas divididas entre cinco pessoas, resultam em quinze pedaços (o todo). Nesse caso, quando as professoras falam em três pedaços não se dão em conta que as pizzas poderiam ter tamanhos diferentes conforme a professora $E$ apresenta : "1/5 + 1/5 + 1/5 dá 3/5 é diferente de 15/5". A Figura 02 ilustra o exposto.

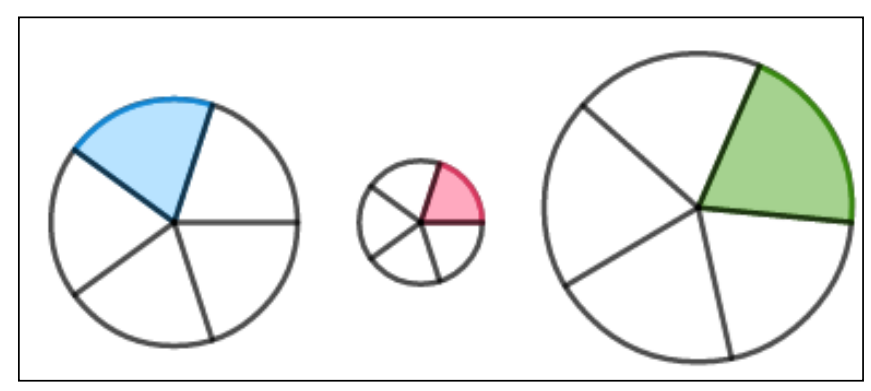

Figura 02: Representação figural para o significado 'quociente'. Fonte: Elaborado pelas autoras. 
O significado fração foi discutido por meio do problema:

Jô, Pat e Cris resolveram fazer um piquenique e combinaram levar sanduíches para o almoço. Jô levou três sanduíches, Pat levou dois e Cris se esqueceu do combinado e não levou nenhum. Assim, resolveram repartir os sanduíches que tinham levado igualmente entre as três, mas cobraram da Cris $R \$ 5,00$ por sua parte. Que parte dos $\mathrm{R} \$ 5,00$ recebeu Jô? E Pat?. (ONUCHIC; ALLEVATO, 2008, p. 89)

Durante a discussão deste problema, a professora B textualizou a sua estratégia de resolução e observou-se o envolvimento coletivo e cooperativo das demais. O Episódio 5 expressa o movimento de (re)elaboração referente ao entendimento do problema proposto.

\section{Episódio 5.}

Professora A: Eu pensei assim: são cinco sanduíches e são três pessoas. Se fosse fazer proporcional aos pedaços de sanduíche cada uma teria comido um sanduíche e 2/3 do outro [...] não sei se fecha.

Pausa.

Professora B: Eu achei que Jô recebeu $R \$ 4,00$ da parte de Cris e a Pat $R \$$ 1,00. É isso?

Professora Formadora B: É, vamos discutir como você pensou.

Professora B: Eu desenhei três sanduíches e os outros dois. No total, tenho 5 sanduíches divididos em 3 pessoas. Então dividi 5 por 3 [...] surgiu uma dízima periódica. Isso pra mim é um inteiro e mais 2/3. Então significa que cada pessoa comeu um sanduíche inteiro e 2/3 do outro sanduíche [...]. Ao total cada uma comeu 5 partes então 5 reais dividido por cinco partes da $R \$$ 1,00 cada parte. Foi assim que eu pensei. Então Jô recebeu $R \$ 4,00$ e Pat recebeu $R \$ 1,00$.

Professora F: Na verdade não é justo porque daí ela comeu então da parte da Jô e não comeu da parte da Pat.

Professora B: Não, mas ela comeu da parte da Pat. É que Pat tinha levado dois sanduíches.

Professora F: Ela está certa (referindo-se à professora B), ela comeu a parte dela e cedeu.

Professora C: Ela (a Cris) pagou só aquele pedacinho.

Professora formadora B: Por que vocês disseram que era injusto gurias?

Professora C: Não, agora não.

Professora F: Agora não acho mais.

Professora B: Eu não achei que fosse injusto, porque tira a parte que me pertence né, o excesso que eu levei eu cedo pro outro. 
Durante a discussão do problema, identificou-se que a professora B apresenta o significado quociente ao expressar: "No total, tenho 5 sanduíches divididos em 3 pessoas", ou seja, cada pessoa comeu 5/3 de sanduíche. Esse entendimento não foi percebido e nem discutido durante a socialização da resolução do problema pela professora B. Entretanto, após a leitura da resolução proposta em Onuchic e Allevato (2008, p.89-90) atentou-se para o significado quociente. Talvez isso tenha acontecido, visto que o foco de discussão foi o significado fração e evidencia, novamente, que diferentes significados surgem entrelaçados durante a resolução de um mesmo problema.

O significado razão foi discutido por meio do problema:

Duas jarras iguais contêm misturas de álcool e água nas razões $3 / 5$ (três para cinco), na primeira jarra e $3 / 7$ (três para sete) na segunda. Juntando-se os conteúdos das duas jarras qual será a razão entre álcool e água na mistura resultante?' (ONUCHIC; ALLEVATO, 2008, p. 95)

Inicialmente a professora formadora B chama a atenção para o fato de que as propriedades da razão são diferentes das propriedades da fração, conforme o Episódio 6.

Episódio 6.

Professora Formadora B: [...] e agora quando a gente pensa na razão, as operações com frações não valem mais, porque somar duas razões não é a mesma coisa que somar duas frações né?

Professora A: pra mim ainda é...

Discute-se qual o significado da razão na frase: a jarra contém "misturas de álcool e água nas razões 3/5, ou seja, para cada cinco litros de água utilizam-se três litros de álcool. As professoras participantes não levam em consideração que as jarras possuem a mesma capacidade, conforme apresentado no problema. Nesse sentido, destaca-se a intervenção das professoras formadoras e o movimento de compreensão acerca do problema proposto, conforme assinalado no Episódio 7. 


\begin{abstract}
Episódio 7.
Professora Formadora A: [...] nesse caso podemos considerar que a capacidade é de oito litros.

Professora F: [...] e depois a outra três sétimos, daí dá dez.

Professora Formadora A: Dá dez, mas a capacidade continua de oito litros...

Professora B: Mas daí já deu dezoito litros . (referindo-se à soma 8 (primeira jarra)+ 10 (segunda jarra))

Professora F: Não, mas daí daria dezesseis porque a capacidade é de oito litros em cada jarra.

Professora B: [...] três mais cinco que eu vou usar proporção se eu tenho três de álcool e cinco de água, então eu tenho oito, que deu a primeira jarra, no outro eu tenho dez litros.

Professora A: Não! A razão na segunda jarra é três para sete e a capacidade é de oito litros.

Professora B: Vou dividir o dez... dá 0,8... caiu a ficha.

Professora Formadora B: [...] se eu tenho oito litros e a razão é três pra sete... três pra sete significa que eu vou ter dez partes, certo? Como a capacidade é oito litros, dividido em dez partes, cada parte tem que ter 0,8 litros.
\end{abstract}

Para a finalização da resolução do problema as professoras formadoras recorrem ao registro figural, conforme a Figura 03.

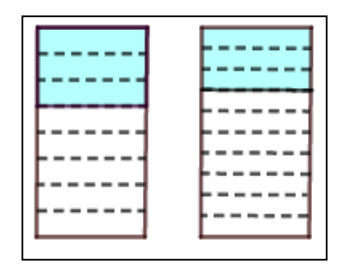

Figura 03: Representação figural para a resolução do problema.

Fonte: Elaborado pelas autoras.

Considerando que as jarras possuem a capacidade de 8 litros e que na segunda jarra a razão entre álcool e água é de três para sete, então tem-se 10 partes de 0,8 litros. Desse modo, tem-se 2,4 litros de álcool e 5,6 litros de água. Assim, juntando-se os conteúdos das duas jarras, a razão entre álcool e água é de:

$$
\frac{3+2,4}{5+5,6}=\frac{5,4}{10,6}
$$

Ou seja, para 10,6 litros de água utilizam-se 5,4 litros de álcool totalizando 16 litros, conforme considerado inicialmente que cada jarra possui a capacidade de 8 litros. 
Neste momento, foi retomado que a soma de razões é diferente da soma de frações e observou-se nas discussões realizadas 0 desconforto das professoras em verbalizar que uma razão é uma fração, conforme passagem, a seguir.

Professora A: [...] já menti para meus alunos. Muitas vezes eu já disse para os meus alunos que a razão é como se fosse uma fração.

Conforme Onuchic e Allevato (2008, p.99) “[...] não raro, razões são consideradas como frações, uma vez que a partir de seu símbolo, a notação barra fracionária, induz a um tratamento semelhante." Nesse sentido, o exposto pelas autoras também é textualizado pelas professoras participantes da formação.

Professora A: Eu acho que a razão não deveria ser representada como é. Professora D: Não deveria utilizar essa barra de divisão. Porque essa barra remete a uma divisão.

Por fim, pode-se inferir, após o estudo realizado, que as professoras denotam novas compreensões acerca dos números racionais e seus significados, conforme sinalizado nos segmentos, a seguir.

Professora A: [...] mas parece que um desconstrói o outro (referindo-se aos diferentes significados). Assim, dá uma sensação de andar no escuro.

Professora B: É que agora são outros ângulos que a gente olha [...] mexendo naquilo que a gente tinha como certo.

Destaca-se que esse movimento de (re)configuração está marcado nas interações discursivas estabelecidas no grupo e apresentadas em alguns episódios neste texto: nas discussões e dúvidas apresentadas durante a resolução dos problemas propostos e nos conflitos estabelecidos na relação das professoras com esse instrumento simbólico o que potencializou reflexões sobre o agir docente e novas formas de (re)organizar o seu trabalho.

\section{Considerações}

O objetivo deste trabalho consistiu em compreender como o professor de Matemática (re)configura os diferentes significados do número racional a partir da formação continuada. Para tal, à luz do primeiro nível de análise do ISD, 
identificaram-se e discutiram-se os conteúdos tematizados em quatro encontros de formação continuada nos quais os diferentes significados do número racional foram estudados.

A identificação do conteúdo tematizado permite inferir que as professoras participantes da formação continuada (re)configuram os significados do número racional durante as interações discursivas estabelecidas no grupo: nas discussões apresentadas durante a resolução dos problemas propostos; nas dúvidas que surgiram durante a resolução dos mesmos; nos conflitos estabelecidos na relação das professoras com esse instrumento simbólico o que potencializou reflexões sobre o agir docente e novas formas de (re)organizar o seu trabalho.

Ressalta-se que neste texto, embora se tenham realizado a análise e resolução das questões da prova da OBMEP no terceiro e quarto encontros de formação, apenas apresentaram-se a quantificação dos significados privilegiados nas provas. As interações discursivas advindas da resolução dessas questões constituirão um novo corpus de análise, o qual deverá ampliar as compreensões referentes às (re)configurações dos significados do número racional, pelas professoras participantes da formação.

\section{Referências}

BAKHTIN, Mikhail. Estética da Criação Verbal. São Paulo: Martins Fontes, 1992 [edição original: 1984].

BAKHTIN, Mikhail. (VOLOCHÍNOV). Marxismo e filosofia da linguagem. 8. ed. São Paulo: Editora Hucitec, 1997 [edição original: 1977].

BONOTTO, Danusa .L.; GIOVELI, Izabel. Formação continuada de professores de matemática e uma experiência envolvendo material de Cuisenaire. In: VII JEM, 2018, Passo Fundo-RS. Anais do evento. Passo Fundo-RS, 2018.

BRASIL. Base Nacional Comum Curricular. Ministério da Educação. Brasília, DF, 2018. Disponível em: http://basenacionalcomum.mec.gov.br/wpcontent/uploads/2018/02/bncc-20dez-site.pdf. Acesso em: outubro de 2018.

BRONCKART, Jean -Paul. Atividade de linguagem, textos e discursos: por um interacionismo sócio-discursivo. São Paulo: EDUC, 2012. 
Atividade de linguagem, discurso e desenvolvimento humano. Campinas: Mercado de Letras, 2006.

\section{O agir nos discursos: das concepções teóricas às concepções dos} trabalhadores. Campinas: Mercado de Letras, 2008.

MACHADO, Ana Raquel.; BRONCKART, Jean-Paul. (Re-)configurações do trabalho do professor construídas nos e pelos textos: a perspectiva metodológica do Grupo AlterLael. In: MACHADO, A.R. e colaboradores(Orgs.). Linguagem e Educação: o trabalho do professor em uma nova perspectiva. Campinas: Mercado de Letras, 2009, p. 31-77.

ONUCHIC, Lourdes R.; ALLEVATO, Norma Suely G. As diferentes "personalidades" do número racional trabalhadas através da resolução de problemas. Bolema, Rio Claro, ano 21, n. 31, p.79-102, 2008. 